\title{
REVIEW
}

\section{SUBACUTE MYELO-OPTICO-NEUROPATHY, A NEW NEUROLOGICAL DISEASE PREVAILING IN JAPAN}

\author{
REISAKU KONO \\ * Director, Central Virus Diagnostic Laboratory, National Institute of Health, \\ Nakato, Musashimurayama, Tokyo 190-12, Japan \\ ** Chairman, The SMON Research Commission, Ministry of Health and Welfare
}

(Received: June 7th, 1971)

\section{CONTENTS}

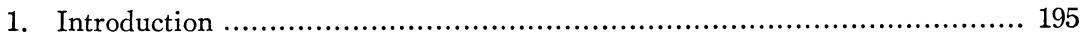

2. SMON as a clinical entity ......................................................... 197

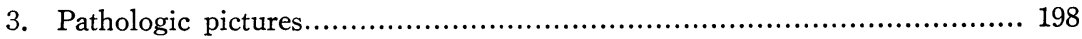

3.1 Nervous system........................................................... 198

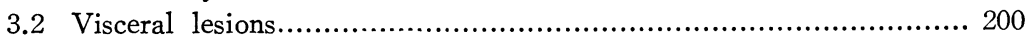

4. General epidemiological pictures.................................................. 200

5. Hypotheses on etiology................................................................ 205

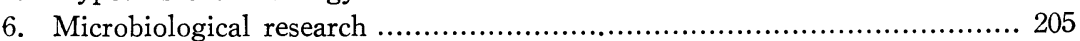

7. A new hypothesis: Clioquinol as etiological agent ............................ 206

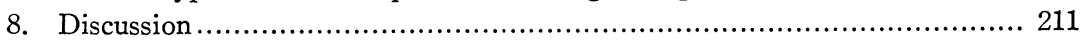

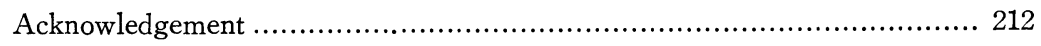

References...................................................................... 213

Addendum.................................................................... 216

\section{INTRODUCTION}

In the end of 1950's Japanese physicians noticed an occurrence of a myelitis-like illness preceded by abdominal symptoms, such as abdominal pain or diarrhea or both, before the appearance of neurological disorders. First reports came from two districts, from the central parts by Kusui and Kamide (1958), Wakayama Prefectural Medical School, and by Takasaki et al. (1961), Mie Prefectural Medical School, and from the northern parts of Japanese mainland, by Sugata, Katayama and Hanakago (1960), Tohoku University Medical School, and by Seino et al. (1960), Yamagata City. Then, similar reports followed one after another, and it became evident in 1963 or so that there was a sharp increase in sporadic cases and some localized outbreaks.

At the beginning, the disease was suspected to be akin to benign encephalomyelitis, similar to Iceland disease (White and Burtch, 1954) or a special type of multiple

甲野 礼作 *国立予防衛生研究所ウイル ス中央検查部 東京都武蔵村山市中藤 ** スモン調査研究協議会会長 
sclerosis accompanying abdominal symptoms, and was taken by physicians as Devic's disease in some outbreaks. However, soon these concepts were abandoned when the clinical analysis proceeded and the accumulated evidences of post-mortem findings uncovered a unique feature of the disease. Accordingly, it was once called "Nonspecific encephalomyelitis with abdominal symptoms" and a symposium (1965) on this subjects was held at the 61st Annual Meeting of the Japanese Society of Internal Medicine in Kyoto (President: Prof. M. Maekawa), 1964. Most participants agreed that the disease represented a new clinical entity. Among the participants, Tsubaki, Toyokura and Tsukagoshi (1965) proposed to designate the ailment as subacute myelooptico-neuropathy of unknown etiology, abbreviated to SMON, because of two reasons: (1) subacute or acute onset of the disease, and (2) principal neuropathological changes were of degenerative in nature, consisting of non-inflammatory pseudosystemic degeneration involving the peripheral nerves, post-lateral columns of the spinal cord and retrobulbar optic nerves. Since then, SMON has been widely used because of its suitability, shortness and convenience.

From the beginning, viral etiology has been suspected, hence Kono (1966) has engaged in etiological study of SMON from virological point of view from 1958, but he has never isolated any viral agent of etiological significance from feces, spinal fluid, throat swabs, autopsied nervous materials or other specimens, while Okuda, Takedatsu and Shingu (1965) claimed to have isolated echovirus type 21 from patient's materials and to have obtained serological evidences revealing echo 21 as the cause of SMON in 1965. However, no other investigators could confirm their findings.

Since severe outbreaks of SMON had occurred in two rural areas in Okayama Prefecture since 1967, the Ministry of Health and Welfare organized a Special SMON Research Commission in the fall of 1969. The purpose of the study was to elucidate its epidemiology and etiology, and to find effective therapeutic and preventive measures.

SMON Research Commission has taken multidisciplinary approach to solve the problem, hence the members of the group composed of epidemiologists, microbiologists, clinicians, neurologists, neuropathologists, and pharmacologists: the members were 40 in the first year and 64 in the second year. SMON has scarcely been known outside of Japan from the reasons that SMON seems to confine to occur in Japan and most of the voluminous publications were written in Japanese and a few in English (Symposium, 1965; Maeda, 1970; Sobue et al., 1971; Tsubaki, Honma and Hoshi, 1971). However, our foreign collegues have got information on this new disease occurring in Japan more and more but fragmentarily. Accordingly, an increasing urgent demand had arisen to obtain more comprehensive knowledge on SMON in a readable form. In the course of studies during one year and a half, our SMON Research Commissicn came across several interesting findings. Considering these situations, we felt the time has come to do so. In order to fulfil the above requirements, this paper will concern itself with a general review on SMON and the recent results of research conducted by scientists of SMON Research Commission. Accordingly, those who want to know more detail should consult the original papers appeared in Japanese medical journals, although we will publish all the original works in English in the near future. Since the studies are continued, this review does not constitute an official final view of SMON Research Commission but is an interim review of the existing findings. 


\section{SMON AS A Clinical ENTity}

One of the first achievements of the study group was to set up the clinical diagnostic guideline of SMON to secure as accurate notification as possible from doctors. Since we have no laboratory tests at present, the diagnosis depends completely upon the clinical picture, as is shown in Table 1 . It is composed of two cardinal and several other frequent but not always occurring symptoms of diagnostic value. Figure 1 shows some of the typical feature of SMON cases.

Table 1. Diagnostic guideline of "SMON" (1970)

Cardinal symptoms.

1. Abdominal symptoms (abdominal pain, diarrhea, etc.): preceding to neurological symptoms in most cases.

2. Neurological symptoms :

a. Acute or subacute onset.

b. Sensory disturbances predominant: bilaterally in the lower part of the body, particularly in the distal part of the lower extremities; its upper margin obscure; paresthesia (stick something under the sole, strangling sensation of the ankle or the calf, etc.) common and often the first sign of the disease.

Other frequent symptoms.

1. Deep sensory disturbance common.

2. Motor disturbances:

a. Muscle weakness of the lower extremities not rare.

b. Pyramidal signs (exaggeration of the tendon reflex of the lower extremities, Babinski's reflex, etc.) often observed.

3. Slight sensory and motor disturbances sometimes in the upper extremities.

4. Following symptoms may accompany:

a. Bilateral blurred vision leading to blindness.

b. Cerebral and psychologic disturbances.

c. Greenish fur on the tongue and greenish pigmentation of feces.

d. Bladder and proctoparalysis.

5. Prolonged clinical course; relapse not rare.

6. No abnormality found in the blood and the spinal fluid by ordinary laboratory tests.

7. Extremely rare in infants and children.

Since it is not the principal aim of this paper to describe the symptomatology of SMON in detail, the author hopes that the clinical features of SMON are to be understood through Table 1 and Fig. 1, and the following additional remarks.

Such abdominal symptoms are important in SMON as abdominal pain or diarrhea or both. Clinical analysis (Ando and Sobue, 1969) revealed two kinds of abdominal disorder, namely, (1) chronic disorder of the alimentary tract lasting over years, and (2) a prodromal type of the abdominal symptom before the onset of neurological sign. It is suspected by proponents of the clioquinol hypothesis, which will be described later, that the second type might represent the side effect of the drug.

As for neurological signs, the unique dysesthesia is most characteristic and distresses the patients for many years after other symptoms have subsided. 


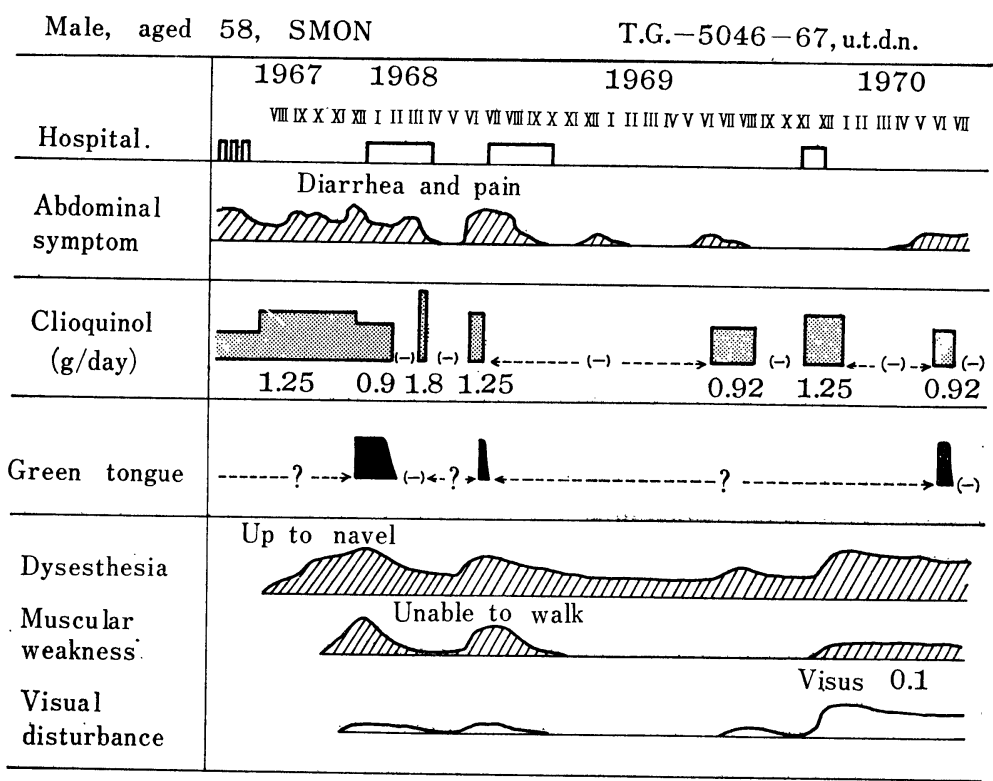

Fig. 1. Typical clinical course of SMON. (After Takasu)

According to the nation-wide survey (SMON Research Commission, 1970) made at the end of 1968, the followings are the distinct symptoms of the disease:

(1) More than $90 \%$ of them had paresthesia and dysesthesia of the lower extremities; (2) weakness of legs was found in $73.8 \%$, more prone to female and older person over 60 , and complete paraplegia in $11.5 \%$; and (3) total blindness was found in $2.5 \%$ and blurred vision in $18.9 \%$; bladder and proctoparalysis were found in $8.9 \%$.

As for prognosis, relapse is not rare. About $50 \%$ of patients can return to the normal life in 1 to 2 years with some residual sensory disorder, whereas 10 to $15 \%$ are completely unable to take care themselves. The disease develops often in hospitalized patients with other chronic illnesses, such as malignant neoplasms, chronic nephritis, tuberculosis, diabetes etc. Deaths are usually ascribed to any of complications such as decubitus, cystitis or other intercurrent infections, but it is also true that SMON per se can cause death. Most workers believe that the fatality rate of SMON is about 3 to $5 \%$.

\section{Pathologic Pictures}

\subsection{Nervous System (Matsuyama, 1965; Shiraki and Oda, 1969; Shiraki, 1971)}

As seen in Fig. 2, the most essential pathological findings are restricted to the both central and peripheral nervous tissues and the optic nerve (approximately $20 \%$ of the patients develop impaired visual functions).

In typical cases the optic nerve develops demyelination and proliferation of glial cells, especially in the papillomacular bundle. Ganglion cells in the inner ganglion cell layer of the retina are, sometimes, disintegrated as well (Okuda and Ueno, 1970). 
MEDULLA
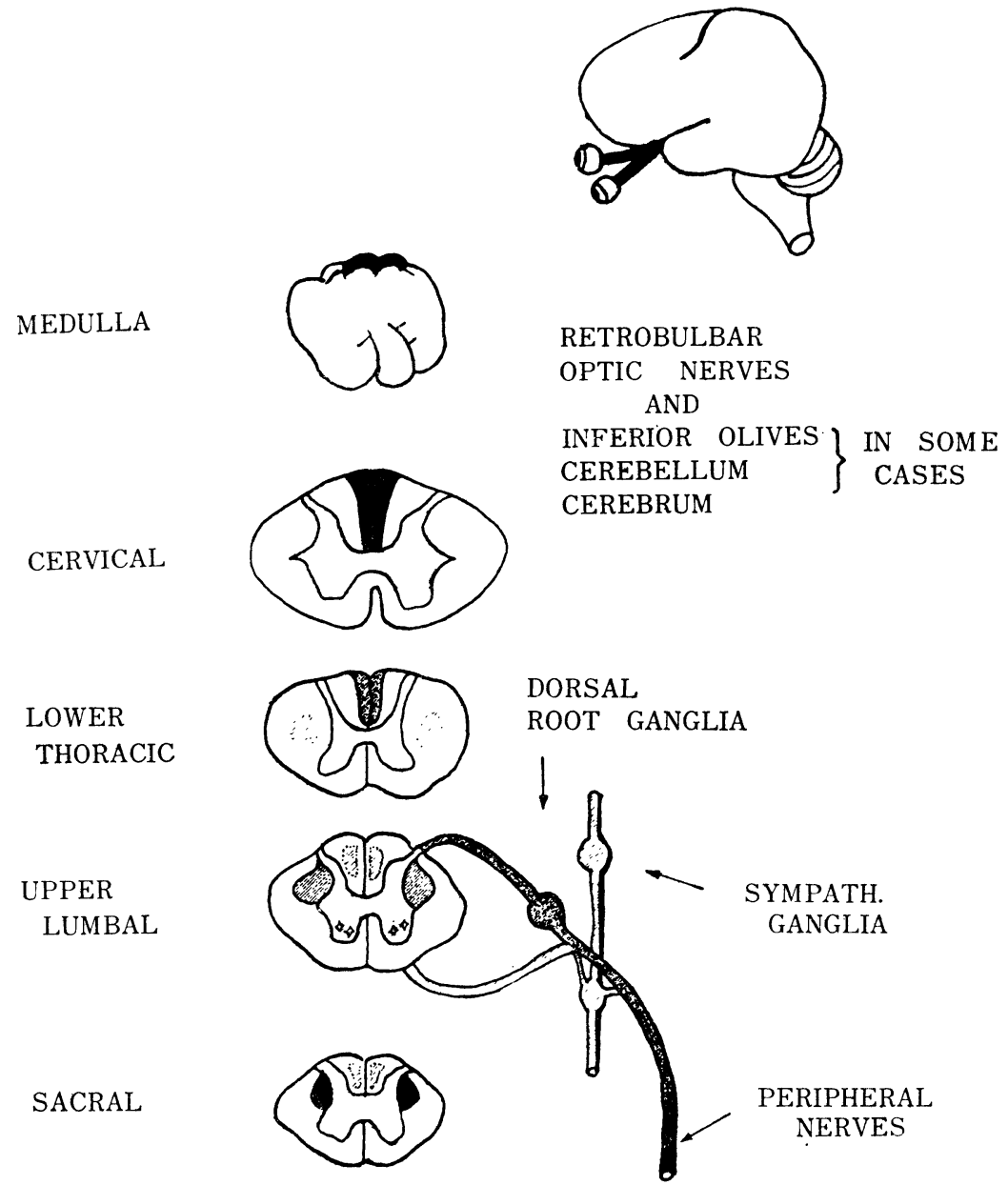

Fig. 2. Diagram illustrating sites of lesions. (After Toyokura et al.)

Sites are shown by shadowed or black areas: darker the shadow, severer the change.

In the spinal cord symmetrical degeneration of the posterior and lateral tracts with a maximum involvement at the lower thoracic to the upper lumbar level is seen. The posterior tract is affected without exception. The changes are in the lumbar level, gradually restricted to the Goll's tract at the upper level of the cord where disappearance of myelin becomes more clear-out. Involvement of the cortico-spinal tract, on the other hand, is less frequent as compared with that of the posterior tract, distinct at the lumbar cord and becomes more reduced in the upper thoracic and the lower cervical cord. In short, two long tracts represent degenerative changes which are more distinct in their peripheries. Degeneration of the lumbar dorsal root ganglia accompanied by degeneration and disintegration of ganglion cells is a prominent feature; the peripheral sensory nerves extending from the dorsal root to the distal part of the lower extremities are severely affected. Axonal alterations are prominent particularly in acute or subacute cases, while demyelination and proliferation of Schwann's cell 
nuclei or collagen fibers or both are also noted in subchronic to chronic cases. Similar but less sever degenerative changes are not infrequently found in the autonomic nerves, especially at the distal part of the vagus and sympathetic nerves, resulting in innervation of the digestive tracts. Nérve cells of the inferior olivary nucleus are occassionally disintegrated, and gliosis and hypertrophic astrocytosis occur. Throughout the involved nervous tissues there is hardly any inflammatory reaction.

\subsection{Visceral Lesions}

Due to complicating diseases and therapeutic measures often applied rather vigorously, the changes occurring in the viscera are difficult to assess. The liver shows various changes which are in general mild; the hepatic cells tend to be rather atrophic. In the spleen, there are no changes indicating reactive responses. Accumulation of mucus in the dilated lumen of the pancreas is discussed from the possible involvement of the autonomic nervous system. The renal lesions observed are very variable and believed to represent complications rather than significant primary changes.

In the digestive tract several pathological changes possibly significant in some way or other have been noticed but not constantly. In several autopsied cases, hyperkeratinization of the dorsum of the tongue accompanying greenish discoloration was found. The intestinal mucosa biopsied in a few cases was atrophic. Severe atrophy of the colonic mucosa associated with plasmocytic infiltration and remarkable deposit of pseudomelanotic pigment was noticed in several cases (Takeuchi, Sakurama and Tomio, 1970). In almost all cases, however, advanced postmortal changes obscured pathologic lesions even if such had been present and made correct evaluation impossible. Virus-like bodies demonstrated by one of the members of the committee are not accepted as meaningful due to the same difficulty (Takeuchi, Sakurama and Tomio, 1970).

Noticeable changes of the intramural neural plexus appeared lacking.

In summary, evaluation of the visceral lesions has met great difficulty, but the major organs, such as the liver, kidney, spleen, heart, lung and incretory organs appear to reflect only complicating diseases or effects of treatment, while it is suggested that the digestive tract may possibly harbor some significant changes. These changes must be evaluated carefully in the light of other data.

\section{General Epidemiological Pictures}

The nation-wide survey of SMON patients who visited the medical institutions has been conducted since 1967 by SMON Research Commission (1970, 1971a); it revealed that the patients have totaled 7,856 (confirmed cases, 5,048; suspected cases, $2,808)$ as of the end of October 1970. It also disclosed that the patients diagnosed for the first time in each year were 1,172 in 1966 and before, 1,276 in 1967, 1,743 in 1968, 1,988 in 1969 and 1,135 in 1970 (until October) and indicated the gradual increase year after year with exceptional decrease in 1970.

Figure 3 shows the prevalence rate of total SMON patients per 100,000 population as of the end of October 1970 in every prefecture; Fig. 4 represents the annual incidence rate of SMON patients newly diagnosed in 1967 and 1968. It appears that both the prevalence and incidence rates of SMON patients were higher in the southwestern part of Japan. 


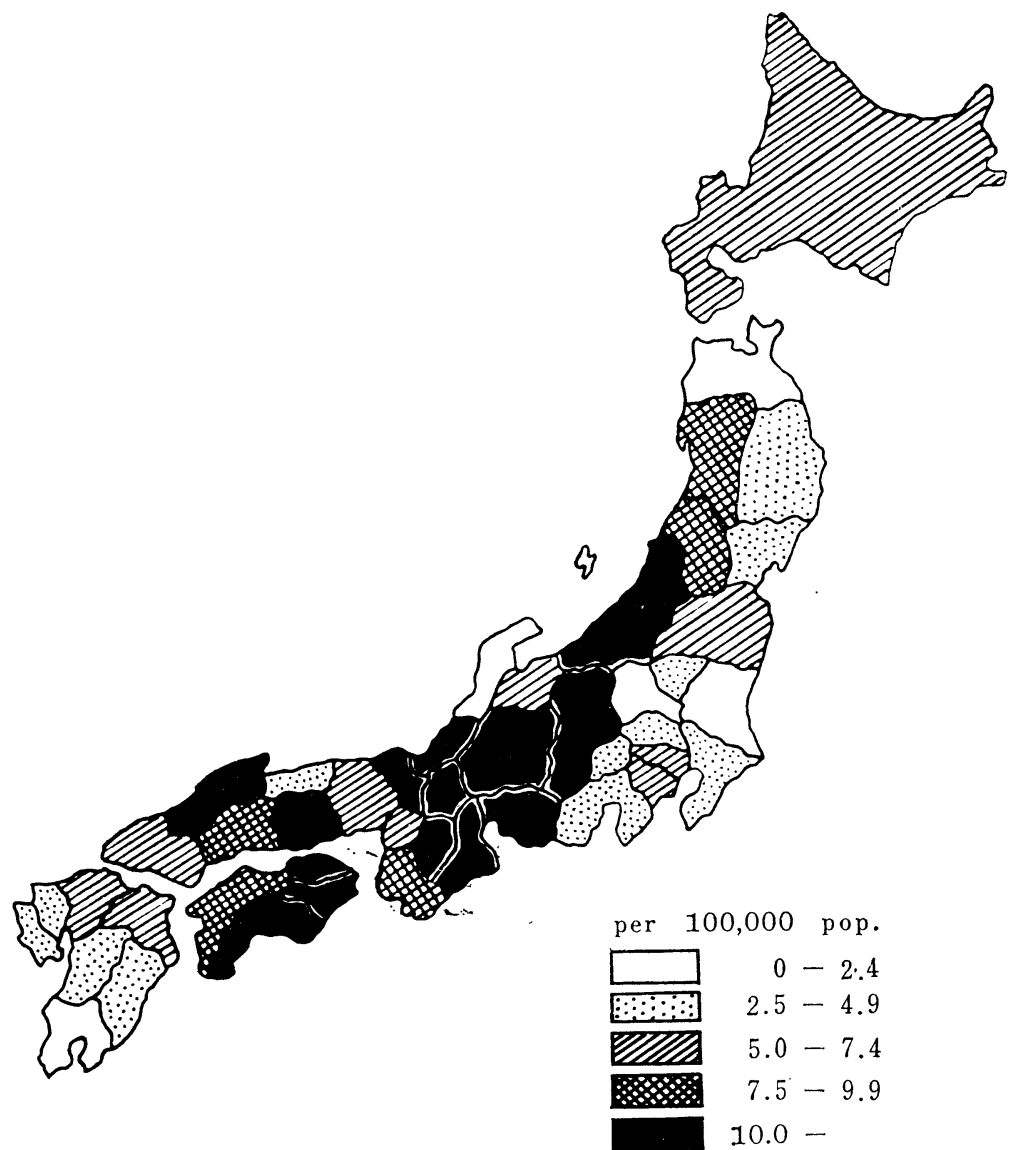

Fig. 3. Prevalence rate of total SMON patients by prefecture per 100,000 population.

As of the end of October 1970.

Number of patients : 7,856

Rate $\quad: 7.8$ per 100,000 population

It is of great concern from both the medical and public health viewpoints whether or not SMON is infectious. The epidemiological evidences mentioned in Table 2 seem to support the infectious nature of this disease; on the contrary, it is hardly considered to be infectious on clinical and pathological grounds as shown in Table 3 . It is quite clear, however, that these contradictory findings must be incorporated into one in order to reach the final conclusion on the pathogenesis of SMON.

As for the seasonal distribution of this disease, it was found that the SMON patients newly diagnosed in each month were most prevalent in late summer for the years of 1967, 1968 and 1969 as shown in Fig. 5, but it is noteworthy that the monthly occurrence of patients in 1970 did not change greatly from January through July, followed by the sudden drop after August. It was suggested that this fact might be closely related with the governmental decision made on 8 September 1970 


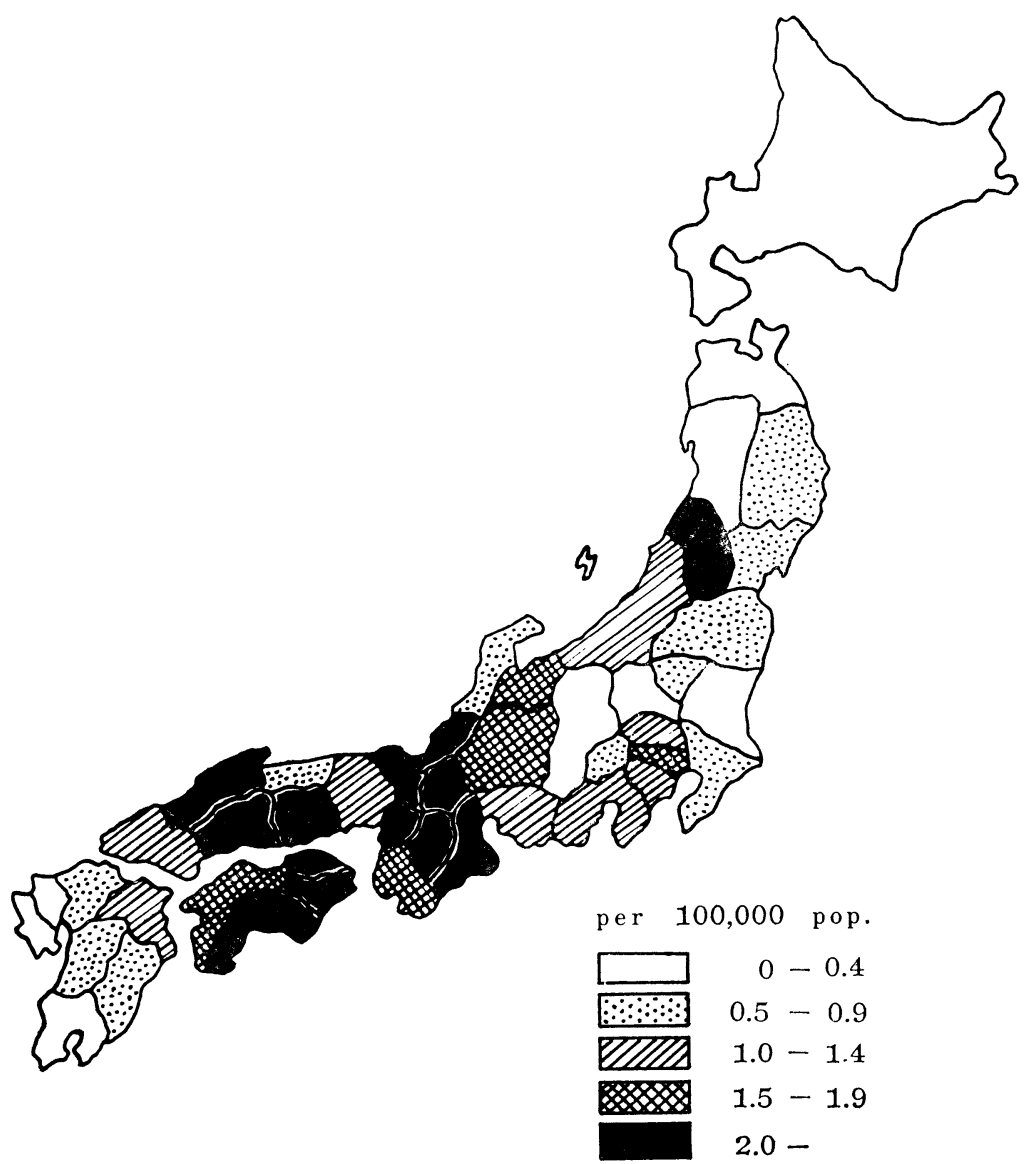

Fig. 4. Annual incidence rate of SMON patients newly diagnosed in 1967 and 1968 by prefecture per 100,000 population.

Number of patients: $3,019(1967: 1,276,1968: 1,743)$

Annual rate $\quad: \quad 1.5$ per 100,000 population

Table 2. Observations suggesting infectious nature of SMON

1. Endemic occurrence in a small city or a town for several years, and quiescent thereafter.

2. Familial aggregation of the cases was sometimes observed.

3. There were hospital- or doctor-centered outbreaks.

4. Second cases occurred most often 2.5 months after the first in the family outbreak in Okayama.

5. Morbidity by profession is higher in medical and paramedical personnels.

6. Seasonal prevalence in summer.

7. No correlation with particular industry or mining. 
Table 3. Observations unexplicable by the infection hypothesis.

1. "SMON" is a new disease appeared in the latter half of 1950's in Japan; similar disease has seldom been reported in other countries.

2. Rare in children and high morbidity in middle or old aged women.

3. In most areas the disease was sporadic: it was hard to trace contact between cases.

4. Clinical course: (1) no fever, rash and other symptoms suggesting infection; (2) blood and spinal fluid showed no abnormality.

5. Pathohistology: (1) main pathologic changes are symmetrical axonal degeneration and demyelination in Goll's and side pyramidal tracts of the spinal cord, the optic nerve, and the peripheral nerves of the lower extremities; (2) no inflammatory change; (3) topography of the pathologic changes most closely resemble to the subacute combined degeneration of the spinal cord. These changes remind us an outcome of metabolic disorder, vitamin deficiency or intoxication.

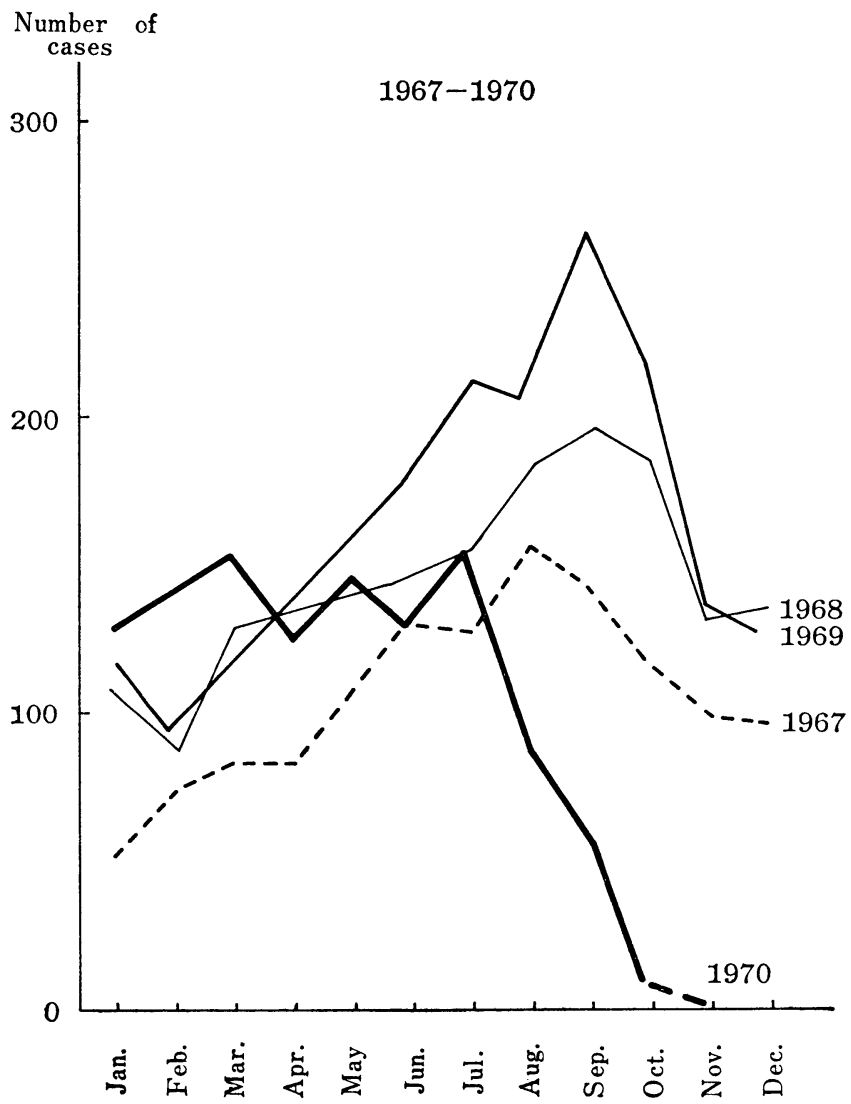

Fig. 5. Number of SMON patients newly reported by month. 
prohibiting the sale of clioquinol and broxy-quinoline.

The prevalence and incidence rates of SMON by age and sex shown in Figs. 6 and 7 are rather impressive because children under 10 years of age are affected extremely rarely, while the peaks of both prevalence and incidence curves are formed at the age of 60-69 in either sex, and the rates for female are in average twice as high as those for male. Sex difference in the rates increases by age, particularly after

As of the end of October 1970

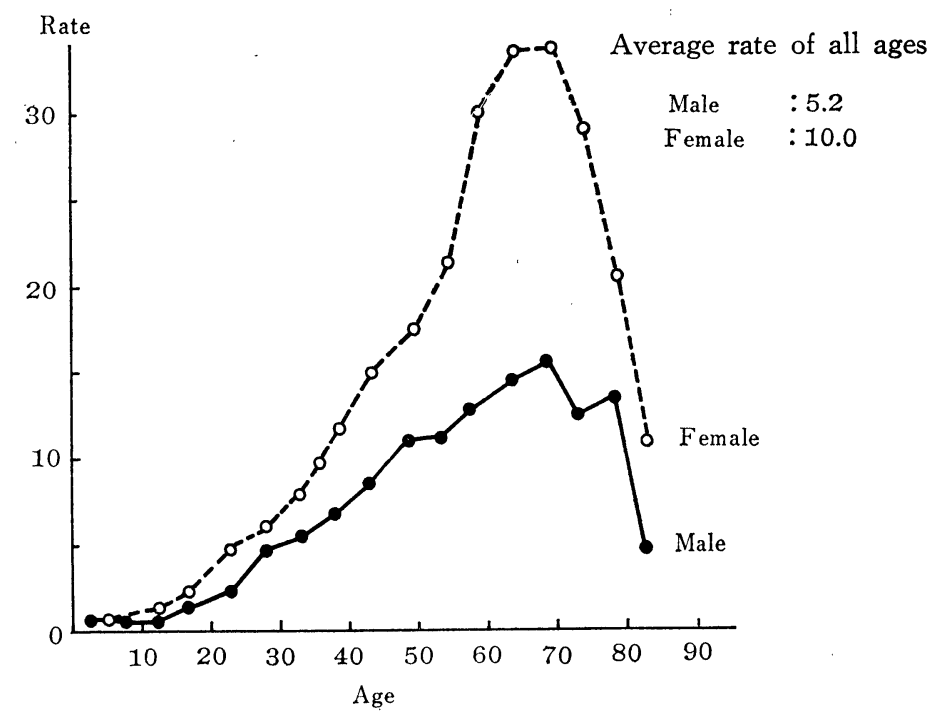

Fig. 6. Prevalence rate of SMON patients by age and sex per 100,000 population.

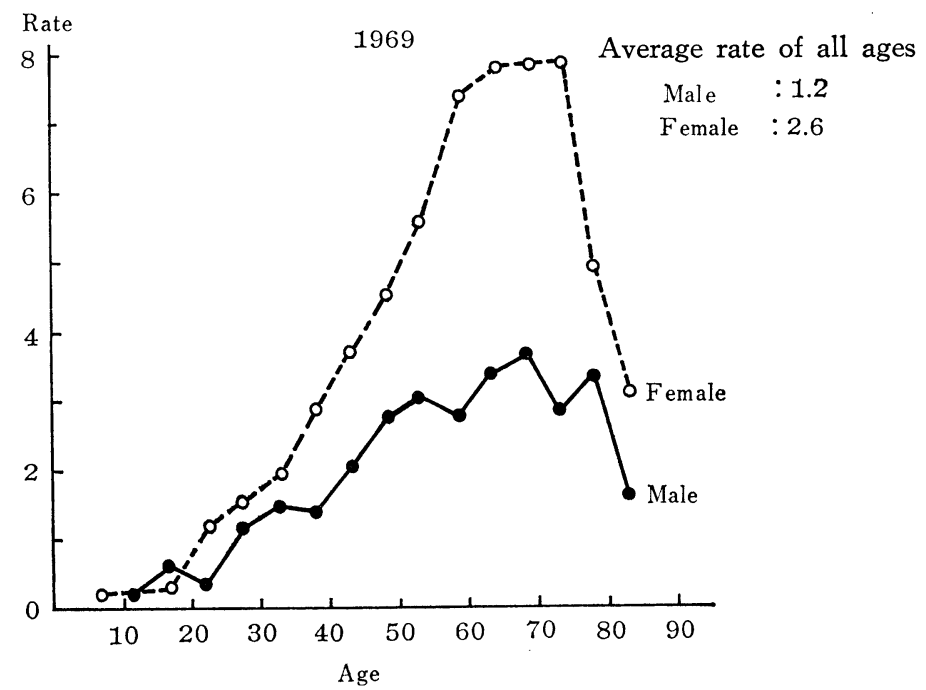

Fig. 7. Incidence rate of SMON patients by age and sex per 100,000 population. 
20 years of age, with maximum difference at the peak age.

So far as the epidemiological phenomena of SMON are concerned, it has been elucidated that various factors are positively related with the occurrence of SMON patients, e.g. familial and institutional aggregation, time and space aggregation, previous history of pulmonary tuberculosis and abdominal operation, hospital workers, taking of clioquinol, etc.

\section{Hypotheses ON ETIOLOGY}

There are several conceivable hypotheses on etiology of SMON. The first is intoxication. The extensive use of pesticides in agriculture, environmental contamination with industrial waste, and excessive use of drugs have been present since the 1950s in Japan with her high economic and industrial developments.

The quantity of agricultural biocides used per unit area in Japan is the largest in the world, but the attack rate of SMON among farmers is lower than those of other professions (Aoki et al., 1970; SMON Research Commission, 1970). The levels of cholinesterase in the serum and the red blood cell and of BHC accumulated in the fat tissue in SMON patients showed no difference from those in the age-matched healthy control (Egashira and Watanabe, 1970; Hiraki and Iwasaki, 1971). Therefore, a direct effect of biocides on SMON is hard to conceive. Industry and mining could be suspicious sources of environmental contamination leading to mass intoxication, but these are not present in any of the epidemic or endemic areas of the disease. It is possible that food additives or residual chemicals in foods from environmental contamination may be responsible. It has been shown that the accumulation of heavy metals like mercury and biocide like BHC in the human body are rather high in Japan. Therefore, these factors, though may not be direct causative agents, have to be taken into consideration in connection with their supplementary roles in the development of SMON.

Clinicians and neuropathologists ignoring the epidemiology prefer a metabolic disorder and a vitamin deficiency as the causative mechanism. Similar clinical and pathological pictures have been documented in the literature, such as, subacute combined degeneration of the spinal cord which appears after vitamin $\mathrm{B}_{12}$ deficiency (Erbslöh, 1958; Mayer, 1963; Bebin, 1968; Verjaal and Timmermans, 1967), tropical neuropathy in Jamaica (Montgomery et al., 1964) and Nigeria (Osuntokun et al., 1968), nontropical sprue (Smith, 1955) or celiac disease (Cooke and Smith, 1966), carcinomatous and diabetic neuropathy. One hypothesis would be that the infection with SMON agent of the intestinal tract may cause a disturbance of absorption of an essential nutrient, with the subsequent development of the neurological symptoms.

Neuro-allergic manifestation sometimes gives similar sex and age distributions, but we have no other evidence for it with SMON.

Lastly, we have an infectious etiology hypothesis. Since infection seemed to be the most plausible cause of the disease at the beginning, extensive efforts have been directed to find the microbial etiological agent.

\section{MicRobiological Research}

Several investigators isolated CPE agents from the spinal cord, spinal fluid, blood 
and feces. They were echovirus type 21 (Shingu et al., 1965), coxsackie A group viruses (Sakurada et al., 1966), herpes-like new virus (Inouye, Nishibe and Nakamura, 1970), enterovirus of unknown type (Nakazawa et al., 1968, 1969) etc. However, the etiological role of all these isolates has not been confirmed by other investigators. Another suspect is Mycoplasma which was isolated from the fur of the tongue and feces (Honma et al., 1971). Some strains were proved toxic in nerve tissue culture of rats. The strains isolated were typed as $M$. orale type $1, M$. sarivarius, and $M$. hyorhinis but other types might be involved.

It has been anticipated that there would be a change of the intestinal flora causing some disturbance in the host metabolism and leading to SMON. The results of bacteriological studies of the intestinal flora of SMON patients showed that number of Bacteroidaceae, Catenabacterium, Bifidobacterium, and Lactobacillus and the rate of detection of Catenabacterium and Lactobacillus were significantly smaller than in the healthy controls (Nakaya et al., 1970; Nakaya, 1971). But there is no definitive evidence that any of such changes is the primary cause of the disease.

Antibodies against many enteroviruses, herpes group of viruses, measles, some respiratory viruses and other ordinary viruses have been searched for in patient's sera, but no particularly high titer was found. However, some sera showed higher agglutinin titers to Salmonella organisms incidentally isolated from SMON patients at their terminal stage to death (Ozawa et al., 1970; Nakaya et al., 1970; Nakaya, 1971). In other patients higher antibody titers against EB and Marek's disease viruses were demonstrated. One investigator reported a higher incidence of complement fixing antibody against the Mycoplasma pneumoniae antigen. From these serological evidences no definitive trend could be obtained. We do not know what these results imply.

Electronmicroscopic observation of virion was attempted by several workers in ultra-thin sections of patient's autopsy or biopsy materials. No virus-like particles were seen in the CNS (Ikuta, Chichibu and Iwasaki, 1968), but one investigator reported a virus-like particle with a diameter of $170 \mu \mathrm{m}$ in average in the epitherial cell of the small intestine (Takeuchi et al., 1970).

\section{A New Hypothesis : Clioquinol* as the Etiological Agent}

Takasu, Igata and Toyokura (1970) noticed that the fur of the tongue was coloured green in some SMON patients. We thought that this observation might be a key to solve the problem. Honma, who is a specialist in Pseudomonas sp., tried to isolate that organism, because we ascribed first the green fur to infection with that organism. It was isolated, however, only on a few occasions.

In May, 1970, Igata, Hasegawa and Tsuji (1970) found two SMON patients excreting greenish urine. Since large amount of greenish urine sediment was obtainable, it was subjected to chemical analysis performed by Tamura et al. It was soon discovered by Yoshioka and Tamura (1970) that the green pigment appeared in the urine and feces of SMON patients was the iron (III) chelate of clioquinol (5-Chloro-7Iodo-8-Hydroxyquinoline) and also that the urine contained crystals of free clioquinol in a larger amount (about $0.1 \mathrm{~g}$ per $500 \mathrm{ml}$ ). Ikeda (1970) found high iron and zinc

\footnotetext{
* It is designated "chinoform" in Pharmacopoeia Japonica. Chinoform is more common in Japan, but in this article the author takes the name "clioquinol" according to the WHO usage.
} 
contents of the green fur of the tongue. Later, Imanari and Tamura (1970) confirmed the presence of clioquinol in the green fur by gas chromatography.

Tsubaki is the first neurologist who suspected that SMON is caused by medication with clioquinol (Tsubaki, Honma and Hoshi, 1971). It has long been believed that clioquinol is a rather safe drug without serious side effects because of its poor absorption from the intestine. However, the above observation of excretion of free clioquinol in the urine by two patients indicated that clioquinol was absorbed, that is to say, the old belief was not correct.

The energetic surveys made by Tsubaki's group in seven hospitals revealed the following facts: (1) one hundred and sixty-six of 171 SMON patients had been administered with clioquinol before neural symptoms appeared. In other words, $96 \%$ of them took this drug, this figure was exceedingly high as compared with the rate of administration of other common drugs; (2) neural symptoms appeared most of ten at the time when total dose of the drug reached 10 to $50 \mathrm{~g}$; (3) the mean interval between the drug administration and the onset of neural symptom was 48.8 days at a daily dose of $600 \mathrm{mg}$ and 29.4 days at a daily dose of $1,200 \mathrm{mg}$; (4) large dosage tended to cause severer illness; (5) in A Hospital, where SMON broke out in 1968, its monthly rise and fall paralleled with number of clioquinol tablets consumed; (6) they found 29 SMON cases $(11.0 \%)$ of 263 patients with enteric disorders who had been treated with clioquinol, but no neurological complication was found in 706 similar cases without such treatment (Tsubaki et al., 1971).

Table 4 summarizes the results of case-history studies of some institutional incidences of SMON. Kuratsune et al. (1971) found 5 suffering from SMON among 115 persons treated with clioquinol for diarrhea and other abdominal symptoms; whereas none was SMON among 217 persons who had similar symptoms but received no such treatment $(\mathrm{p}<0.005)$. Aoki et al. (1971) studied 4,318 patients in a hospital and disclosed that among 532 cases treated with clioquinol $17(3.2 \%)$ developed SMON; 4 of 3,786 cases $(0.1 \%)$ without clioquinol intake were diagnosed as such $(\mathrm{p}<0.001)$.

Yoshitake and Igata (1970) investigated 155 patients who were operated on the adbominal viscera in I Hospital from 1966 to June 1970. In this hospital, SMON

Table 4. Incidence of SMON in the groups of patients with or without clioquinol administration

\begin{tabular}{lcccl}
\hline \multicolumn{1}{c}{ Authors } & $\begin{array}{c}\text { Clioquinol } \\
\text { administration }\end{array}$ & SMON $(\%)$ & Non-SMON & Remarks \\
\hline $\begin{array}{l}\text { Yoshitake } \\
\text { et al., } 1970\end{array}$ & Yes & $34(43.6)$ & 44 & Post-surgery \\
\hline $\begin{array}{l}\text { Kuratsune } \\
\text { et al., 1971 }\end{array}$ & Yo & $0(0.0)$ & 77 & \\
\hline Aoki et al., & No & $5(4.3)$ & 110 & Enteric disorders \\
1971 & Yes & $17(3.2)$ & 515 & Enteric disorders \\
\hline $\begin{array}{l}\text { Tsubaki } \\
\text { et al., 1971 }\end{array}$ & No & $4(0.1)$ & 3,782 & $\mathrm{p}<0.001$ \\
\hline
\end{tabular}


occurred among post-surgery patients. Since it was suspected of a specific infection, many patients were treated prophylactically with clioquinol after the operation. The results were remarkable in that 34 of $78(43.6 \%)$ who had taken $1.35 \mathrm{~g}$ of clioquinol per day suffered from SMON about 1 to 3 weeks after the operation and the rest 77 who had not taken clioquinol recovered without complication. There was no distinct difference between SMON and non-SMON patients concerning basic illness, mode of operation, volume of blood transfusion and application of antibiotics.

Ohmura (1971) found after an outbreak of dysentery (Shigella flexneri 2) in 1965 that 5 of 26 patients developed SMON. Reinvestigation of old clinical records available revealed that all the patients had been treated with clioquinol, that all the 5 SMON patients were older females averagely aged 63 years and that none of 18 younger persons ( 6 males, 6 females and 6 children) had such neurologic complication. The dose of clioquinol was $2 \mathrm{~g} /$ day for adults and about half for children. The total dosage was about 40 to $50 \mathrm{~g}$ for either a SMON or non-SMON case.

These results seem to indicate that the attack rate of SMON may vary from a few to several ten percent of those who have taken clioquinol. Post surgical condition, enteric bacterial infection and other accessory factors may also be responsible for developing neural disorder.

Similar observations have been made by members of the SMON Research Commission (Tsubaki et al., 1971; Kasai and Kanamitsu, 1971; Nakae et al., 1971; Sobue and Ando, 1971; Kuroiwa, Inoue and Tamura, 1971). It has been confirmed that a common characteristic of SMON is the hospital- or doctor-centered occurrence.

From such information, the Japanese Central Pharmaceutical Affairs' Council advised the Ministry of Health and Welfare to take measures mentioned below on 7 September 1970. Then, the Ministry of Health and Welfare made the following decisions on 8 September 1970, concerning clioquinol and broxy-quinoline:

(1) to prohibit, for the time being, the sale of the two drugs and preparations containing one of them;

(2) to warn all parties concerned, including general public, not to use these drugs or preparations containing either of them;

(3) to notify the prefectural government, in due coures, of the procedure to be taken in those cases where the drug must be administered, i. e. for the treatment of disease such as acrodermatitis enteropathica;

(4) not to approve, until otherwise is noticed, any new registration of the manufacture and importation of the two drugs.

The SMON Research Commission made a larger scale retrospective study headed by Kusui to know how many SMON patients had actually taken clioquinol 6 months before or any time after the neurological involvement (SMON Research Commission, 1971 b). Eighteen neurologists of the Research Commission were asked to fill in the inquiry form on each patient observed by themselves. All the items of the inquiries were compiled and analysed in the Department of Epidemiology, Institute of Public Health. The overall results showed that 632 of 742 cases $(85.2 \%)$ had been treated with clioquinol but $110(14.8 \%)$ had not during the 6 months before the onset of the neural symptoms.

It is most interesting whether or not the banning the sell of clioquinol influences the further development of new cases. The SMON Research Commission has asked the prefectural health departments to submit monthly report of new cases. The data 
compiled by Shigematsu at the end of December 1970 showed a dramatic drop of newly reported cases since September 1970. The time of the decrease roughly corresponded to the appearance of the clioquinol hypothesis proposed by Tsubaki on the newspaper of 7 August and the official ban on 8 September. The actual monthly incidence was 150 in July, while only 8 and 1 in October and November 1970 respectively (Fig. 5).

The SMON Research Commission also tcok an action to collect information on new SMON cases diagnosed by the neurologists of the Research Commission in 1970 and 1971; the total number from 1 January to 7 September 1970 was 371 and from 8 September 1970 to 31 January 1971 dropped to 19 (6 of them had taken clioquinol, 9 had not and 4 unknown). This type of approach is considered more accurate than the official notification mentioned above, because the diagnosis was more reliable and it included non-reported cases. According to this survey, the number of new SMON patients also decreased dramatically after September, 1970, as shown in Fig. 8. Such dramatic drop of the new monthly cases is considered to be far beyond a natural trend of decrease and might be ascribed to banning the sell of clioquinol.

From the clinico-epidemiological studies made by many workers, supporters of the clioquinol hypothesis generally agreed that (1) the daily dose and the duration of administration of the drug are of significance; (2) the dose-response relationship is

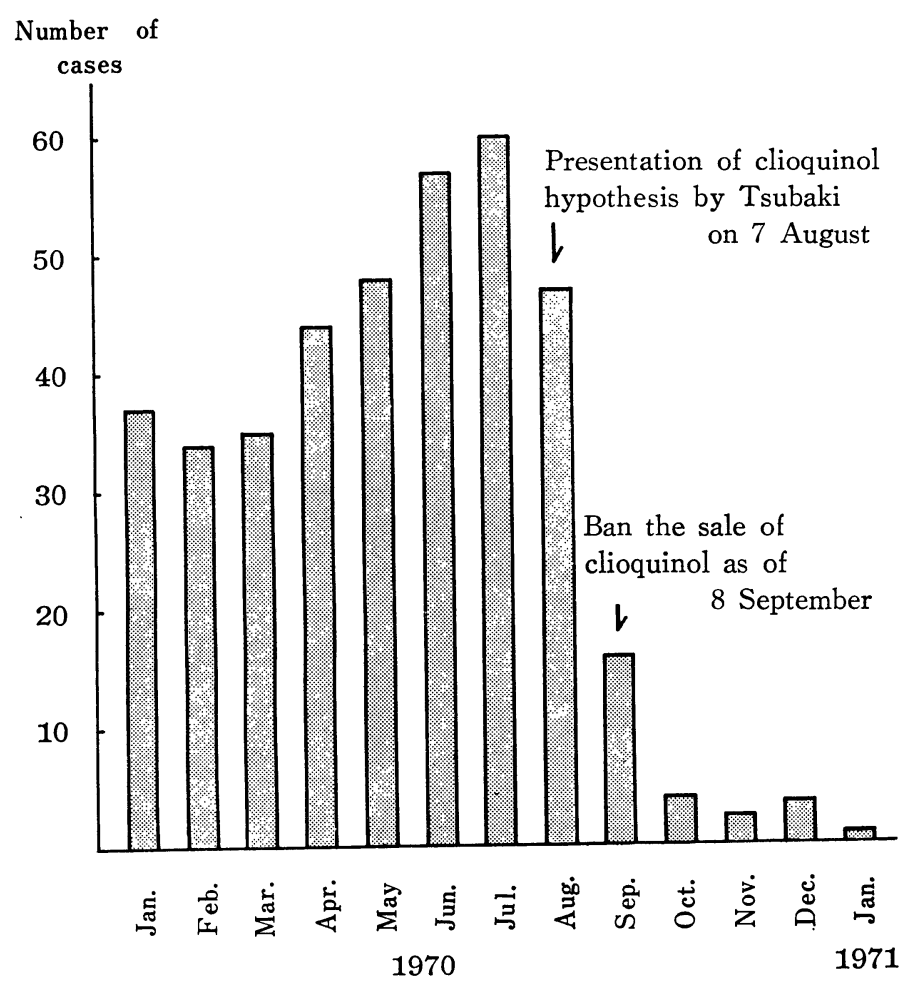

Fig. 8. Number of SMON patients newly diagnosed monthly by the hands of neurologists of the SMON Research Commission in 1970 and 1971. 
rather different from those of other toxic substances, namely, 40 to $50 \mathrm{~g}$ of total drug intake brought a plateau of the incidence rate and higher dose paradoxically did not increase the rate; (3) the dose of clioquinol for children was smaller and the duration of medication was less than 1 week in over $90 \%$ of them, hence the risk of clioquinol intoxication might be low and thus SMON is rare in children; (4) old females are more sensitive to the toxic action of clioquinol than males of the same age at the same dose of the drug; (5) there is considerable variation in sensitivity to clioquinol among individuals.

Nakae and Igata (1971) established a mathematical equation for the relationship between the daily dose and its duration of administration; they designated the curve obtained by the equation as the minimum dose-duration curve, concluding $0.44 \mathrm{~g} /$ day or less would by no means do any harm and a certain dose-duration pattern is necessary for manifestation of the intoxication.

Another evidence supporting the clioquinol hypothesis came out from neuropathology. Tsutsumi and Ogawa (1970) found by autopsy a parallelism between severity of pathologic changes in the nervous system and the dose of clioquinol intake. Tsukagoshi, Togi and Toyokura (1971 a, b) observed similar dose-response relationship in histopathological study of the sural nerve biopsy of SMON patients. The latter results revealed a similar dosage level leading to axonal degeneration of the peripheral nerve with the theoretically deduced dosage mentioned above.

Animal experiments with mice, rats, guinea pigs, hamsters, rabbits, dogs, chickens and monkeys have been carried out by several investigators. Rats and hamsters seem to be less sensitive, but other animals are more or less intoxicated by oral, intravenous, or intraperitoneal administration of the drug. Most intoxicated animals exhibited a symmetrical weakness or paralysis of the hind legs, in which a degenerative change of the myelin sheath or axon or both were noted in the peripheral nerves but none in the spinal cord. One of the most promising experiments was made by Tateishi et al. (1971); they demonstrated pathological changes of SMON similar to those in human cases, combined degeneration of the spinal cord, in a dog given with $72 \mathrm{mg} / \mathrm{kg} /$ day of clioquinol. The dog showed paralysis of the hind legs on day 20 and was killed on day 78. Generally speaking, animal experiments are still at a preliminary stage but hopeful for the future.

An interesting observation of rabbits was reported by Miyoshi et al. (1971). First, they noted chemical similarity between clioquinol and oxin (8-Hydroxy Quinoline), which is known as a diabetogenic drug, then they injected 60 to $90 \mathrm{mg} / \mathrm{kg}$ of clioquinol intravenously and demonstrated that it was diabetogenic substance. This finding may shed light on the mode of action of clioquinol and pathogenesis of SMON.

About the retention of clioquinol in human tissues, Imanari et al. (1971) detected more than $0.5 \mu \mathrm{g}, 0.3 \mu \mathrm{g}$ and $0.1 \mu \mathrm{g}$ of free clioquinol per $\mathrm{g}$ of the liver, the mesenteric adipose tissue and the sciatic nerve, respectively, from a SMON patient after a nine-month stopping of administration of clioquinol.

Ogata et al. (1971) reported that the whole body count of mice received orally 5 $\mu c$ of ${ }^{131}$ I-labelled clioquinol was about $40 \%$ after $24 \mathrm{hr}$. A half decay time of radioactivity in the serum was $12 \mathrm{hr}$; the radioactivity reached a plateau after 3 days, when the drug was given daily and whole body count was performed. Besides, they demonstrated retention of a small amount of clioquinol in the peripheral nerves $(N$. 
ischiadicus).

In a human volunteer given orally, $100 \mu \mathrm{c}$ of ${ }^{131} \mathrm{I}$-clioquinol with $0.5 \mathrm{~g}$ of nonlabelled clioquinol, Kosaka et al. (1971) revealed that the excretion rate in $24 \mathrm{hr}$ was $61.7 \%$ in feces and $10.1 \%$ in urine.

Takasu et al. (1971) studied by radioautography the fate of clioquinol given to mice: ${ }^{131}$ I-labelled clioquinol was rapidly absorbed from the injection sites and distributed in the whole body, especially intensively in the gall-bladder and the bile duct, which suggested entero-hepatic circulation of the drug. It was also demonstrated that the whole body count was about $10 \%$ after 3 days and declined to 2 to $3 \%$ after one week. It is of interest that radioactivity was demonstrated by macro-autoradiography as early as several minutes after the injection of the drug in the central as well as perpheral nervous systems.

Experiments of the same type with ${ }^{125} \mathrm{I}$ - or ${ }^{14} \mathrm{C}$-labelled clioquinol have been carried out by several workers and very interesting results accumulated to demonstrate the neurotropism of clioquinol.

\section{Discussion}

The recent results described in the previous chapter strongly suggest a relationship of clioquinol to the development of SMON, but of cause we are still cautious of reaching a final conclusion.

I stated that SMON has two contradictory faces, by which we can interprete the disease in two ways, either infectious or non-infectious, but they should be fused into one. And it looks likely that clioquinol can play such a linking role. Two to 5 items in Table 3, listed as unexplicable observations by the infection hypothesis, are not contradictory to the clioquinol intoxication hypothesis. Particularly, the extreme rarity of child cases, which is hard to explain by the infection, is more easily explicable by the lower dose and shorter duration of the drug administration. Many of items suggesting infectious nature of SMON are also interpreted from the clioquinol intoxication. The hospital- or doctor-centered outbreak which has often been observed is not hospital infection but is most likely one of iatrogenic diseases.

It is certain that SMON-like diseases which can be connected with clioquinol intake are rare outside of Japan, but some reports suggest that a clioquinol-induced neurologic disorder indistinguishable from SMON has occurred in Europe (Kaeser und Wüthrich, 1970). Whether the frequent occurrence of SMON in Japan is due to a racial factor, in the mode of administration or in the presence of some accessory factors, should be clarified in the future.

There have also been increasing experimental evidences and clinical observations from outside of Japan indicating that clioquinol and related compounds have neurotoxicity in man (Gohlz and Arons, 1964; Berggren and Hansson, 1966; Etheridge and Stewart, 1966; Strandvik and Zetterström, Kaeser und Scollo-Lavizzari, 1970; Kaeser und Wüthrich, 1970) and animals (Fischer, 1964; Roesch, Roesch and Hoffter, 1965; Püschner und Fankhauser, 1969).

There are, however, several difficulties in the clioquinol intoxication hypothesis. The first difficulty resides in the explanation of outbreaks of SMON lasting for several years in a small city or a town. In Okayama Prefecture, two endemic foci were found in three years from 1967 to 1969, and new cases no longer appeared 
since the latter half of 1969 . Such an outbreak is pretty difficult to interprete by clioquinol alone. A plausible explanation may be that there is a basic prevalence of enteric disease upon which clioquinol is widely used for treatment resulting in accumulation of its intoxication. In Yubara-cho, one of the epidemic spots in Okayama Prefecture, Shibata (1971) noticed an increase in frequency of such enteric disease which was prevalent during the SMON outbreak, and observed the development of SMON among those diarrhea cases. Unfortunately, nature of the basic illness was not known. Secondly, in response to the inquiries about the clinical record of the patients as to whether or not they had taken clioquinol before appearance of neurological symptoms, we encountered negative answers in 10 to $15 \%$ in average. Thirdly, it was observed that relapse occurred without intake of clioquinol, although more often after the clioquinol administration. These facts offered other difficulties in the clioquinol hypothesis. It was found that clioquinol retained in the adipose tissue etc. for many months, hence the drug may be freed from the reservoir at the time of relapse.

On the other hand, being convinced of the infection hypothesis, some scientists of the Research Commission are strongly opposing the clioquinol hypothesis. But no definitive microbial causative agent has ever been confirmed, although some investigators claimed to have successfully isolated echovirus type 21 and a new virus. At the moment, most of the study group believe that viral and other microbial etiology of SMON is unlikely, since there are few convincing evidences supporting virus or other microbes as the etiological agent and fitting in the clinico-epidemiological pattern of the disease.

Even if the clioquinol intoxication hypothesis is valid, we do not know much about pathogenesis of SMON. According to Ukyo (1970), it is likely that there is some metabolic disturbance of vitamin $\mathrm{B}_{12}$ as he found excretion of small amount of methyl malonic acid into urine by SMON patients. As described before, Miyoshi et al. (1971) found that clioquinol is diabetogenic. These data may be of importance to understand the pathogenesis. We need further studies to elucidate the whole picture of SMON.

\section{ACKNOWLEDGEMENT}

Executive Members of the SMON Research Commission, Dr. Y. Egashira, Prof. K. Hiraki, Dr. Y. Ikeda, Dr. K. Kusui, Dr. R. Nakaya, Dr. I. Shigematsu, Prof. H. Shiraki, Prof. Z. Tamura and Prof. Y. Toyokura looked over and constructively criticized parts of manuscript, for which the author is most grateful, though they are in no way responsible for errors or ommissions or the view expressed. The author is also greatly indebted to Prof. K. Ohta for description of pathological findings in viscera, to Dr. A. Igata, Dr. K. Ishii and Dr. T. Takasu for their valuable help in preparing the manuscript.

Since most of the works introduced in this review were performed by all the members of the SMON Research Commission, the author wishes to thank them for their great efforts. All the works were supported by Special Research Promoting Grant from the Bureau of Science and Technology in 1969, and by Special Research Grant of the Ministry of Health and Welfare since 1969. 


\section{REFERENCES * Text in Japanese.}

*ANDO, K. AND SOBUE, I. (1969): Myeloneuropathy accompanying abdominal symptoms, with special reference to analytical consideration of abdominal and neurological symptoms. Saishin Igaku, 24, 2440-2450.

*AOKI, K., OtANI, M., SOBUe, I. AND ANDo, K. (1970): Epidemiological studies on SMON in Aichi Prefecture. Reports of SMON Research Commission, No. 1, 92-122.

Aoki, K., OtANI. M., Sobue, I. AND ANDo, K. (1971): Relationship between chinoform administration and SMON incidence observed in some medical institutes. Presented at the meeting of SMON Research Commission, Mar. 1.

Bebin, J. (1968): Megaloblastic anemias. p. 1044-1048. In J. Minckler (ed.); Pathology of the nervous system. Vol. 1, McGraw-Hill, New York.

BERGGREN, L. AND HANSSON, O. (1966): Treating acrodermatitis enteropathica. Lancet, 1, 52.

COOKE, W. T. AND SMITH, W. T. (1966): Neurological disorders associated with adult coeliac disease. Brain, 89, 683-722.

EGASHIRA. Y. AND WATANABE, Y. (1970): Measurement of acethylcholine-esterase in SMON patients. Presented at the meeting of SMON Research Commission, June 29.

ERBSLÖH, F. (1958): Funikuläre Spinalerkrankung. p. 1526-1601. In Henke-Lubarsch-Rössle (ed.); Hdb. d. spez. Pathol. Anat. u. Histol., XIII/2-B, Springer, Berlin, Heiderberg, New York.

ETHERIDGe, J. E. AND STEWART, G. T. (1966): Treating acrodermatitis enteropathica. Lancet, 1, 261-262.

FISCHER, K. (1964): Herdförmige symmetrische Hirngewebsnekrosen bei Hunden mit epileptiforme Krämpfen. Path. Vet., 1, 133-160.

Gohlz, L. M. AND ARONS, W. L. (1964): Prophylaxis and therapy of amebiasis and shigellosis with iodochlorhydroxyquine. Am. J. Trop. Med. Hyg., 13, 396-401.

HIRAKI, K. AND IWASAKI, I. (1971): Personal communication.

*Honma, Y., Chosa, H., Enomoto, M., Watanabe, H., Tomiyama, T. and Kono, R. (1971): Isolation of mycoplasma from the fur of the tongue and faeces of SMON patients. Japan. J. Clin. Med., 29, 753-758.

*Igata, A., Hasegawa, S. AND Tsuji, T. (1970): On the green pigment found in SMON patients: Two cases excreting greenish urine. Japan. Med. J., No. 2427, 25-28.

IKEDA, Y. (1970): Toxicological studies of SMON etiology. Presented at the meeting of SMON Research Commission, Nov. 13.

*IKUTA, F., ChICHIBU, M. AND IWASAKI, Y. (1968): Electron-microscopic observation of a necropsied case with so-called subacute myelo-optico-neuropathy. Annual Rept. Brain Res. Inst., Niigata Univ., 48-50.

*IMANARI, T. AND TAMURA, Z. (1970): Detection of chinoform from green fur of the tongue of SMON patients. Igaku no Ayumi, 75, 547-548.

Imanari, T., Yoshiga, H., Fukada, J., TAMura, Z., Igata, A. AND Toyokura, Y. (1971): On the chinoform contained in the tissues and urine of SMON patients. Presented at the meeting of SMON Research Commission, Mar. 2.

*INoue, Y., Nishibe, Y. AND NAKAmURA, Y. (1970): A new virus isolated from feces of SMON patients with high frequency. Igaku no Ayumi, 72, 321-322.

KAESER, H. E. AND SCollo-LAVizzARI, G. (1970): Akute zerebrale Störungen nach hohen Dosen eines Oxychinolinderivates. Dtsch. med. Wschr., 95, 394-397.

KAESER, H. E. AND WÜTHRICH, R. (1970): Zur der Neurotoxizität der Oxychinoline. Dtsch. med. Wschr., 95, 1685-1688.

KASAI, M. AND KANAMITSU, M. (1971): Epidemiologic study of SMON in Hokkaido. 2nd Report. Presented at the meeting of SMON Research Commission, Mar. 1. 
*Kono, R. (1966): On the problem of etiology of so-called non-specific encephalomyelopathy. Naika, 17, 889-895.

Kosaka, K., Shimada, Y., Yumoto, Y., Nanba, T., Fukuhara, J. and Kubota, M. (1971): Adsorption of ${ }^{131}$ I-labelled chinoform following the oral administration. Presented at the meeting of SMON Research Commission, Mar. 2.

Kuratsune, T., Nishizumi, M., Kochi, S., Yoshimura, T., Matsuzaka, J. AND Tokutomi, N. (1971): Epidemiologic survey on the relationship between SMON and chinoform. Presented at the meeting of SMON Research Commission, Mar. 1.

Kuroiwa, G., InOUe, H. AND TAMURA, K. (1970): On the relation between SMON and chinoform. Presented at the meeting of SMON Research Commission, Nov. 13.

*Kusui, K. AND KAMIDE, M. (1958): A cured case of hemorrhagic diarrhea accompanying polyneuritic syndrome. Psychiatr. Neurol. Jap., 60, 1220.

MAEDA, K. (1970): Encephalomyelopathy following abdominal symptoms; Epidemiological and follow-up studies, histological changes of Auerbach's plexus and urinary porphyrin. Mie Medical J., 14, 209-233.

*MAtsuyama, H. (1965): Autopsy cases of paralytic patients following abdominal symptoms. Japan. J. Clin. Med., 23, 1956-1960.

MEYER, A. (1963): Nutritional deficiencies and disorders. p. 288-323. In Greenfield's Neuropathology, Arnold, London.

Miyoshi, K., Ohta, Y., Kawai, H., Nakano, M., Matsuoka, T., Ohshima, K., Yagita, S., Harada, H., Kosaka, M., Nishikawa, K. ANd OHNo, F. (1971): SMON or the chinoform intoxication and diabetes. Presented at the meeting of SMON Research Commission, Mar. 2.

Montgomery, R. D., Cruickshank, E. K., Robertson, W. B. And McMenemey, W. H. (1964): Clinical and pathological observations on Jamaican neuropathy. A report on 206 cases. Brain, 87, 425-462.

*NAKAE, K. AND IGATA, A. (1971): A theoretical consideration of relationship between SMON and chinoform intake. Igaku no Ayumi, 76, 667-669.

Nakae, K., Yamamoto, S., Igata, A. AND Kojima, T. (1971): Epidemiologic study of SMON in Toda and Warabi areas. 2nd Report. Presented at the meeting of SMON Research Commission, Mar. 1.

*NAKAYA, R. (1971): Bacteriological and serological study of SMON. Japan. J. Clin. Med., $29,759-765$.

*Nakaya, R., Yamazaki, K., Yoshida, Y., NAKano, E., INUGami, Y., Goto, N., Shimada, N., Hirota, S., Takagi, A., Iwano, I., Kono, R. And Ishit, K. (1970): Results of bacteriological and serological study of SMON patients admitted in Ihara City Hospital, Okayama Prefecture. I. Bacteriological study of feces of SMON patients including a fatal case. Igaku no Ayumi. 75, 120-122.

*Nakazawa, T., TsurumizU, T., Kato, Y., Komiya, H., Yoshiba, K. and Maruyama, S. (1968): Some findings of a virus isolated from SMON patients. Clin. Neurology, 8, 443.

*Nakazawa, T.. Tsurumizu, T., Kato, Y., Komiya, H., Yoshiba, K. and Maruyama, S. (1969): On the pathogenicity of a virus isolated froin patients with encephalomyelitis accompanying abdominal symptoms. Clin. Neurology, 9, 654.

Ogata, M., Tomokuni, K., Motonami, H., Shimada, Y., Kosaka, K., Ando, J., Watanabe, M., TAteishi, J. AND OHtsuki, S. (1971): Metabolism of ${ }^{131}$ I-labelled chinoform in the animal body. Presented at the meeting of SMON Research Commission, Mar. 2.

OHMURA, I. (1971): Clinico-epidemiologic observations between SMON and chinoform. Presented at the meeting of SMON Research Commission, Mar. 1.

*Okuda, K., Takedatsu, H. AND Shingu, M. (1965): On the etiology of so-called non- 
specific encephalomyelitis following abdominal symptom; Special reference with virus isolation. Japan. Med. J., (No. 2156), 8-13.

*OKUDA, K. AND UENO, H. (1970): Histo-pathology of the optic nerve and eyeball in SMON. Acta Soc. Opthalm. Jap., 74, 1145-1151.

OSuntokun, B. O. (1968): An ataxic neuropathy in Nigeria. Brain, 91, 215-248.

*Ozawa, A., Goto, Z., Kojima, I. AND KATAOKA, K. (1970): Salmonella meleagridis isolated from feces of SMON patients and its agglutinin. Igaku no Ayumi, 74, 71-72.

PüsChNeR, H. UND FANKHAuser, R. (1969): Neuropathologische Befunde bei experimenteller Vioform-Vergiftung der weissen Mäuse. Schw. Arch. f. Tierheilkunde, 3 371-379.

Roesch, E., Roesch, A. UND Hoffter, D. (1965): Polyneuropathie durch 5-Nitro-8-Hydroxychinolin in Tierexperimenten. Arch. f. Toxikologie, 20, 313-322.

*Sakurada, N., OKuhara, K., Sato, N. AND IIdA, H. (1966): On the clinical description of patients from whom Coxsackie viruses were isolated in Hokkaido, 1964. Report of Hokkaido Inst. Public Health, 16, 47-50.

*Seino, S., Konno, J., Hasegawa, I., Shoji, K., Mito, S. AND Otomo, H. (1960): On the cases of disseminated encephalomyelopathy with prodromal enteric disorder. J. Japan. Soc. Int. Med., 49. 1344-1345.

ShiBATA, B. (1971): Personal communication.

*Shingu, M., NAKagawa, Y., TAketatsu, H. AND OKudA, K. (1965): Isolation of echo type 21 virus from patients with " infectious column myelitis" following abdominal signs. J. Japan. Assoc. Inf. Dis., 39, 139-144.

SHIRAKI, H. (1971): Neuropathology of subacute myelo-optico-neuropathy, " SMON ". Japan. J. Med. Sci. Biol., 24, 217-243.

*SHIRAKI, H. AND ODA, M. (1969): Neuro-pathology of "SMON". Saishin Igaku, 24, 2479-2509.

Smith, W. T. (1955): Neuropathological changes associated with idiopathic steatorrhea. Ecerpta med., Ser. VIII, 8, 860-861.

*SMON Research Commission (1970): Results of nation-wide survey of SMON patients. Reports of SMON Research Commission, No. 1, 4-38.

SMON Research Commission (1971 a): Results of nation-wide survey of SMON patients. 2nd Report. Presented at the meeting of SMON Research Commission, Mar. 1.

SMON Research Commission (1971 b): Survey of chinoform administration in SMON patients. Presented at the meeting of SMON Research Commission, Mar. 1.

Sobue, I., Ando, K., IIdA, M., Takayanagi, T., Yamamura, Y. and Matsuoka, Y. (1971): Myeloneuropathy with abdominal disorders in Japan. Neurology, 21, 168-173.

STRANDVIK, B. AND ZetTerströ̀, R. (1968): Amaurosis after broxyquinoline. Lancet, 1, 922-923.

*Sugata, M., Katayama, M. ANd Hanakago, R. (1960): Four cases of acute transverse myelitis whom a hot spring therapy was effective. J. Japan. Soc. Int. Med., 49, 323.

Symposium on non-specific encephalomyelitis (Chairman: Prof. K. Kusui, 1965): Japan. J. Med., 4, 177-200.

*Takasaki, H., Fujita, H., Kawakami, S., NAgai, H. And Kodama, M. (1961): Two paraplegia cases during the course of enterocolitis. J. Japan. Soc. Int. Med., 50, 171-176.

*TAKASU, T., IGATA, A. AND TOYOKURA, Y. (1970): On the green tongue observed in SMON patients. Igaku no Ayumi, 72, 539-540.

TAKAsu, T., NAKANishi, T., Toyokura, Y., Matsuoka, R., Kurusu, A., IKegami, S., ETo, H. AND MISONOO, K. (1971): Retention and distribution of ${ }^{131}$ I-labelled chinoform in the mouse body. Presented at the meeting of SMON Research Commission, Mar. 2.

*TAKeUchi, T., SAKurama, N. AND TOMIo, N. (1970): Characteristic pathologic changes and virus-like particles in the intestine of SMON patients. Igaku no Ayumi, 73, 65-68.

*Tateishi, J., IKeda, H., Saito, A., Kuroda. T.. HayahaRA, T. AND OtSuki, S. 
(1971): On the chronically intoxicated dogs with chinoform showing the degeneration of the posterior column of the spinal cord which resembles to the human case of SMON. Igaku no Ayumi, 77, 205-206.

TSUBAKI, T., HONMA, AND Y. HOSHI, M. (1971): Neurological syndrome associated with clioquinol. Lancet, 1, 696-697.

TsUBAKI, T., TOYOKURA, Y. AND TsUKAGOSHI, H. (1965): Subacute myelo-optico-neuropathy following abdominal symptoms. A clinical and pathological study. Japan. J. Med., 4, 181184.

*Tsukagoshi, H., TOGi, H. AND ToyokuRa, Y. (1971 a): On the disorders of the peripheral nerve in SMON. (1) Histopathological investigations of the sural nerve by biopsy. Clin. Neurology, 11, 392-399.

*TSUKAGOSHI, H., TOGI, H. AND TOYOKURA, Y. $(1971 \mathrm{~b})$ : On the disorders of the peripheral nerve in SMON. (2) Consideration of clinical symptoms of SMON and findings of the sural nerve biopsy. Clin. Neurology, 11, 400-406.

TsuTsumi, K. AND OGAWA, K. (1970): On the relationship between patho-morphological ch nges and the dose of chinoform administered. Presented at the meeting of SMON Research Commission, Nov. 14.

UKYo, S. (1970): Vitamin $B_{12}$ metabolism and SMON. Presented at the meeting of SMON Research Commission, June 29.

VerjaAl, A. AND Timmermans, A. H. (1967): Combined degeneration of the spinal cord due to deficiency of alimentary vitamin $B_{12}$. J. Neurol. Neurosurg. Psychiat., 30, 464-467.

White, D. N. AND BJRTCH, R. B. (1954): Iceland disease, a new infection simulating acute anterior poliomyelitis. Neurology, 4, 506-516.

*Yoshioka, M. AND TAMURA, Z. (1970): On the nature of the green pigment found in SMON patients. Igaku no Ayumi, 74, 320-322.

*Yoshitake, Y. AND IgATA, A. (1970): On the SMON cases following post abdominal surgery-Relationship of chinoform administration. Igaku no Ayumi, 74, 598-599.

\section{ADDENDUM}

Report of SMON Research Commission, (1970) No. 1 is cited in the reference literature, comprising general survey and individual studies in epidemiology. Following the above, Reports of SMON Research Commission, No. 2 (Clinical aspects), No. 3 (Etiological studies including the both microbiological and chemical ones) and No. 4 (Pathological studies) were published. These volumes include original works cited in the Reference as "Presented at the meeting of SMON Research Commission on November, 1970, and March, 1971". Although all the reports were printed in Japanese, we will be able to distribute some of them upon request. However, as described in the introduction, we are planning to publish all the original works in English in the future. 